\title{
LA SOBERANÍA DEL ESTADO COMO COMPETENCIA DELEGADA POR EL DERECHO INTERNACIONAL. ANÁLISIS CRÍTICO DE LA DOCTRINA EN UNO DE SUS PRIMEROS GRANDES EXPONENTES
}

\author{
Sergio Raúl Castaño \\ CONICET - Universidad del Norte Santo Tomás de Aquino, \\ S. M. Tucumán, Tucumán, Argentina \\ $\mathrm{N}^{\circ}$ ORCID 0000000330832070 \\ Contacto: sergioraulcastano@gmail.com
}

Recibido: 7 de julio de 2021 Aprobado: 20 de agosto de 2021

Para citar este artículo:

Castaño, S. R. (2021). “La soberanía del Estado como competencia delegada por el Derecho Internacional. Análisis crítico de la doctrina en uno de sus primeros grandes exponentes". Prudentia Iuris, N. 92, pp. 159-183

DOI: https://doi.org/10.46553/prudentia.92.2021.pp.159183

\begin{abstract}
Resumen: El tema general del presente artículo está referido a la consideración de la tesis según la cual la soberanía del Estado consiste en una delegación de competencias conferidas por el Derecho Internacional Público. El objeto específico del trabajo consiste en el análisis crítico de la doctrina de uno de los principales exponentes de dicha tesis en el comienzo del siglo XX, el gran jurista Alfred Verdross (1890-1980), cuyas ideas se basaban en el kelsenismo y en la segunda escolástica.
\end{abstract}

Palabras clave: Soberanía del Estado, Orden internacional, Alfred Verdross. 


\title{
State Sovereignty As A Competence Delegated By International Law. Critical Analysis Of The Doctrine In One of Its First Great Exponents
}

\begin{abstract}
The general theme of this article falls within the consideration of the thesis according to which State sovereignty consists in a delegation of powers conferred by public international law. Specifically, the paper deals with the critical analysis of the doctrine of one of the main exponents of this thesis at the beginning of $20^{\text {th }}$ century, the great jurist Alfred Verdross (1890-1980), whose ideas were founded both on Kelsenism and on Second Scholasticism.
\end{abstract}

Keywords: State Sovereignty, International Order, Alfred Verdross.

La sovranità dello stato come competenza delegata dal diritto internazionale. Analisi critica della dottrina in uno dei suoi primi grandi esponenti

Sommario: Il tema generale di questo articolo rientra nella considerazione della tesi secondo cui la sovranità dello Stato consiste in una delega di competenze conferite dal diritto internazionale pubblico. Nello specifico, il contributo affronta l'analisi critica della dottrina di uno dei principali esponenti di questa tesi all'inizio del XX secolo, il grande giurista Alfred Verdross (1890-1980), le cui idee erano fondate sia sul kelsenismo che sulla seconda scolastica.

Parole chiave: Sovranità dello Stato, Ordine internazionale, Alfred Verdross.

\section{Introducción. La tesis en la tratadística española actual}

Al exponer la nodal cuestión del Estado como sujeto "por excelencia" del Derecho Internacional, el distinguido tratadista y juez del Tribunal Europeo de Derechos Humanos, José Pastor Ridruejo, puntualiza las notas más salientes que explican el protagonismo de la comunidad política en la sociedad internacional contemporánea. Así, destaca, en primer término, el 
rango de soberano del poder del Estado, el cual, expurgado de incrustaciones absolutistas, aparece como un poder no ilimitado; que, jurídicamente, implica la igualdad y la independencia de las comunidades de las que es instancia de dirección; y que ostenta "carácter constitucional" para el orden internacional. Asimismo, remata el autor, la soberanía tiene naturaleza funcional e implica la posesión y el ejercicio de un haz de competencias ${ }^{1}$. Más adelante, Pastor Ridruejo resalta el papel determinante del Estado para el Derecho de Gentes, su función de basamento del Derecho Internacional (con cita del leading case "Nicaragua vs. EUA", del Tribunal de La Haya) y reitera con Carrillo Salcedo que la sociedad internacional constituye una yuxtaposición de Estados soberanos ${ }^{2}$. Ahora bien, las ya mencionadas competencias, en las que consiste la soberanía, se justifican, señala el autor con Basdevant, en la medida en que cumplan con las funciones que les son inherentes. Pero -y es aquí donde aparece más claramente la cuestión que nos ocupará- tales competencias "son concedidas a los Estados por el Derecho Internacional”, pues, en efecto, una de las tareas propias de ese Derecho (y, de hecho, para otros juristas ella es su misión por antonomasia) reside en distribuir las competencias entre los Estados. Por otro lado, cuando el Derecho Internacional atribuye competencias a los Estados puede, además, fijar límites a su ejercicio (caso de la soberanía sobre el mar territorial), en cuyo supuesto tal competencia será, además de atribuida por el orden jurídico internacional, reglada -por el mismo Derecho Internacional. Otras competencias resultan discrecionales: son aquéllas a cuyo ejercicio el Derecho Internacional no le pone cortapisas. Esas competencias, también llamadas "exclusivas" (por el Pacto de la S. d. N.) o "esenciales" -a la jurisdicción interna de los Estados- (por la Carta de la ONU), el Derecho Internacional las atribuye, aunque sin reglamentar su ejercicio. Pastor Ridruejo no deja se acotar que ese espacio (el de las "libertades soberanas") es cada vez más reducido ${ }^{3}$. Cabe recordar enseguida cuáles son los grandes

1 Pastor Ridruejo, J. (2001). Curso de Derecho Internacional Público y Organizaciones Internacionales. Madrid. Tecnos, 277-278.

2 Para esta posición de Juan Antonio Carrillo Salcedo en punto a la soberanía, cfr. también, del mismo autor (1995). Soberanía de los Estados y Derechos Humanos en Derecho Internacional contemporáneo. Madrid. Tecnos, 67. Sobre la cuestión de la soberanía en el Derecho Internacional Público (respecto de las reservas y declaraciones interpretativas a los tratados de derechos humanos, el control de convencionalidad, la pretendida supremacía de los tratados sobre la constitución, la "responsibility to protect", la guerra y la hipótesis de un gobierno mundial), cfr. Castaño, S. (2019). El Estado en el orden internacional. Buenos Aires. EDUCA.

3 Pastor Ridruejo, J. Ob. cit., 287-289. Estudiando precisamente el tema del domaine réservé, Enrique Pecourt coincide con la doctrina aquí expuesta: la soberanía no es sino un conjunto de competencias concedidas por el Derecho Internacional: (1962). La sobe- 
ámbitos de competencia. De acuerdo con el criterio cuasi canónico adoptado por el Derecho Internacional en la línea de la teoría del Estado de Jellinek, el Estado posee tres elementos: gobierno, población y territorio ${ }^{4}$. Luego, necesariamente, las competencias atribuidas al gobierno serán, ante todo, competencias personales y territoriales. Es decir que el imperio y el dominio que el órgano de conducción política ejerce sobre sus ciudadanos y los habitantes de su territorio, sobre éste, sobre los funcionarios del Estado actuando en el exterior, etc., constituirán competencias delegadas por el Derecho Internacional.

La misma noción se encuentra en autores como Antonio Remiro Brotóns. "El principio fundamental de la soberanía, sostiene el distinguido tratadista, responde a la idea de función: se trata del conjunto de competencias atribuidas al Estado por el Derecho Internacional, ejercitables en un plano de independencia e igualdad respecto de los otros Estados"5.

Otra autoridad internacionalista española que adhiere a la idea de que la soberanía es competencia delegada, Manuel Díez de Velasco, llama "competencialista" a la posición por él adoptada. Asimismo, atribuye su paternidad al gran jurista francés Charles Rousseau ${ }^{6}$-quien, efectivamente, había propuesto, al concluir la Segunda Guerra Mundial, una teoría de la independencia del Estado sobre la base de su asimilación a una competencia dotada de exclusividad, autonomía y plenitud ${ }^{7}$.

ranía de los Estados ante la organización de las Naciones Unidas. Barcelona. Sagitario, $26-30$ y 44.

4 Cfr. Jellinek, G. (1905). Allgemeine Staatslehre. Berlín. O. Häring, cap. XIII, 381-420; la Convención Panamericana sobre los Deberes y los Derechos de los Estados, de 1933, en su art. $1^{\circ}$, hace suyo este temperamento de Jellinek, que pareciera formar parte del contenido del Derecho Internacional consuetudinario.

5 Remiro Brotóns, A. et al. (2010). Derecho Internacional. Curso general. Valencia. Tirant lo Blanch, 89, destacado original.

6 Cfr. Díez de Velasco, M. et al. (2013). Instituciones de Derecho Internacional Público, C. Escobar Hernández, ed. Madrid. Tecnos, 284.

7 Cfr. Rousseau, Ch. (1949). "L' indépendance de l'État dans l'ordre international". Recueil des Cours, 73. París. Sirey, 167-253 (especialmente, 220-249). Posteriormente, Rousseau planteará su entera Teoría del Derecho Internacional como un sistema que confiere, reparte y reglamenta competencias en el ámbito interestatal: (1958). "Principes de droit international public”. Recueil des Cours 93. La Haya. M. Nijhoff, 369-559, esp. 394 y ss. Al final de su carrera científica, en una obra de síntesis: (1971). Droit International Public. París. Dalloz, Rousseau enumera todos los supuestos en que se operaría una delegación de competencias originada en el Derecho Internacional, en un trecho que define y circunscribe la noción de soberanía tal como es por él entendida (102-103). 


\section{La aparición de la tesis y su afianzamiento en el ámbito jurídico internacional. Dos versiones fundamentales. Bosquejo del individualismo político- jurídico}

A pesar de su atribución a Charles Rousseau, no es aventurado sostener que la idea que analizamos aparece tras la Primera Guerra Mundial. Si es entonces cuando, en algún sentido, se plantearon los prolegómenos político-internacionales de lo que habría de ser el mundo interrelacionado en el que ahora vivimos ${ }^{8}$, también es cuando aparecen algunas grandes líneas de fuerza doctrinales (en último análisis, principiales) del Derecho actual que identifican o resuelven la potestad soberana del Estado en un haz de competencias delegadas por el ordenamiento internacional.

En dicha encrucijada histórico-política e intelectual se delinean dos importantes corrientes teóricas internacionalistas, fundadas en sendas concepciones de la comunidad política, con principios y talantes doctrinales propios, aunque no contradictorios, contestes ambas en negar la función axial del Estado en el orden internacional -con las principales exigencias, presupuestos y corolarios de tal función. Una de esas corrientes corresponde a la genealogía individualista que reconoce un precedente clave -por su influjo posterior- en Léon Duguit, y que se continúa, ya dentro del Derecho Internacional, en Georges Scelle y Nicolas Politis. Hagamos de sus posiciones una rápida reseña.

No es habitual recordar que la influencia de Léon Duguit en el Derecho Público contemporáneo ha sido profunda y perdurable. Intentemos entonces sintetizar su posición sobre el Estado, con sus consecuencias respecto del orden internacional, con tres pasajes de su célebre Traité de Droit Constitutionnel, que pueden, a su vez, plantearse como tres tesis: el Estado se identifica con la sujeción coactiva9; asimismo, deben desterrarse las hipós-

8 Aunque la llamada "globalización" (en sentido político), según el sugerente libro de Horacio Cagni, habría comenzado con la primera contienda desencadenada por los EUA contra una potencia europea, en vísperas del siglo XX -cfr. Cagni, H. (1999). La guerra hispanoamericana y el inicio de la globalización, pról. de Abel Posse. Buenos Aires. CAEE-Universidad de Sevilla.

9 "Je dis seulement que dans tous les groupements humains ou à peu près on constate en fait un phénomène identique, une différenciation entre les faibles et les plus forts, que j'appelle les gouvernants, que les gouvernants peuvent en fait imposer leur puissance de contrainte, qu'on peut appeler ce fait, du mot traditionnel, le fait Etat [...] le fait irréductible, toujours identique à lui-même, est celui de l'existence d'une puissance politique, d'un Etat, c'est-à-dire d'une puissance de contrainte qui s'impose d'une manière irrésistible aux membres du groupement dans lequel elle existe". Duguit, L. (1921). Traité de Droit Constitutionnel. T. I. París, Fontemoing, 397-398. 
tasis que postulan su personalidad y su soberanía ${ }^{10}$; por último, los sujetos por antonomasia del Derecho Internacional son los individuos ${ }^{11}$. Posteriormente, ya en la posguerra, aparece quien es, sin duda, un jalón significativo para el afianzamiento de la capitis diminutio de la soberanía en el seno de la escuela internacionalista que abreva en esta línea doctrinal. Se trata de Georges Scelle ${ }^{12}$. Como ejemplo de esta posición individualista, delinearemos esquemáticamente, a continuación, las ideas de otro de sus relevantes exponentes, el griego Nicolas Politis, cuya obra, publicada en los Recueil des Cours de la Academia de Derecho Internacional, conoció una polémica repercusión ${ }^{13}$.

En el comienzo mismo de su estudio sobre el Estado y la soberanía estatal, Politis asienta con carácter poco menos que de axioma la idea central que sustenta su doctrina internacionalista: el Estado no constituye sino una pura abstracción. Por su parte, la comunidad internacional representa otra ficción, pero aun mayor. Pues, a su juicio, sólo el individuo es real ${ }^{14}$. Precisamente por eso, en sentido estricto, el Derecho sólo mira al hombre. Es en el individuo donde radica el sujeto, el fin y el fundamento del Derecho ${ }^{15}$.

10 "Bannissons donc une fois pour toutes ces conceptions surannées de personnalité et de souveraineté de l'Etat, qui donnent naissance à des problèmes insolubles, à des discussions interminables et vaines, qui ont toujours été et seront toujours le principe d'une action tyrannique et dictatoriale à l'intérieur et d'une politique aggressive et conquérante à l'extérieur" (Duguit, L. Op. cit., 564-565).

11 "Le droit international se compose, comme tout droit, d'impératifs qui s'adressent aux individus et qui ont pour fondement la solidarité existant entre eux, ou, si l'on préfère, la conscience que les individus ont, à un moment donné, de cette solidarité [...] Si l'on étudiait en détaille droit international moderne, il serait aisé de montrer que la création et le fonctionnement de services publics internationaux devient l'objet par excellence du droit international moderne. L'embryon de société des nations qu'a tenté de créer le traité de Versailles n'est pas, en réalité, autre chose que l'ébauche d'un service public de défense commune" (Duguit, L. Ob. cit., 560).

12 Cfr. Scelle, G. (1919). Le pacte des Nations et sa liaison avec le Traité de Paix, préf. de L. Bourgeois. París. Recueil Sirey (importante etapa en el desarrollo de su doctrina); y su clásico Précis de droit des gens (1932, vol. I; 1934, vol II). París. Sirey; reeditado por el CNRS: París, 1984. Comentando la primera de esas obras, Koskenniemi señala: "In Scelle's utopia, the world is ruled by professional corporations: States -and indeed politics- have become extinct": Koskenniemi, M. (2001). The Gentle Civilizer of Nations: The Rise and Fall of International Law 1870-1960. Cambridge. Cambridge University Press, 267. Para una valoración actual del Précis, vide Kasirer, N. (1987). "A Reading of Georges Scelle’s Précis de droit des gens”. Annuaire Canadien de Droit International, vol. 24, 372-385.

13 Cfr. Politis, N. (1926). "Le problème des limitations de la souveraineté nationale et la théorie de l'abus de droit dans les rapports internationaux". Recueil de Cours 6. París. Hachette, 5-121. Así, por ejemplo, Hermann Heller, en Die Souveränität. Berlín. De Gruyter, 1927, confronta con Politis en varias partes del libro (p. ej., pp. 31-34, 160).

14 Cfr. Politis, N. Ob. cit., p. 6.

15 Cfr. Politis, N. Ob. cit., p. 9. 
La soberanía del Estado es poco menos que anatematizada a lo largo del escrito de Politis. Por momentos se le niega validez; por momentos se la reconoce en su efectividad, pero señalando su papel distorsivo y negativo; por momentos se llama a superarla. En esa línea, Politis afirma que el Estado no es, en realidad, soberano, desde el momento en que se halla sometido a reglas imperativas del Derecho Internacional. Asimismo, para el autor, esa superioridad del Derecho de Gentes sobre la soberanía estatal se manifiesta de modo incuestionable en el instituto de la responsabilidad internacional del Estado ${ }^{16}$.

Un lugar relevante en la exposición de Politis lo ocupa la figura del "dominio reservado (domaine réservé)", figura en la que queda englobada la esfera encomendada por el Derecho Internacional a la discreción decisoria del Estado ${ }^{17}$. Respecto de tales materias, sujetas a la libre decisión soberana, el temperamento de Politis permanece idéntico: se trata de una órbita que el Derecho Internacional "tolera". Pues, de hecho, en el dominio reservado estriba un obstáculo para la paz internacional ${ }^{18}$. Sea como fuere de esto último, para Politis, la soberanía ha sido concedida por el Derecho Internacional a los Estados; y se justifica meramente por el objetivo común que éstos deben cumplir en el ámbito internacional ${ }^{19}$.

La segunda corriente teórica a que se ha aludido procede de Krabbe y Kelsen, y ostenta al racionalismo como su rasgo fundamental; esta corriente tendrá en el primer Alfred Verdross un exponente señero. Si la primera tenderá a negar el papel del Estado al socaire de la impostación del lugar de los individuos y sus necesidades, la segunda buscará resolver los vínculos entre el Estado y el Derecho Internacional en relaciones de subordinación entre un ordenamiento parcial y subordinado y otro total y subordinante $-\mathrm{i}$. e., entre la parte y el todo de un haz (único) de normas.

\section{Específico objeto de este artículo}

Plantearemos en lo que sigue las líneas fundamentales de la doctrina temprana de Alfred Verdross, por ser, tal vez, el más conspicuo exponente de las dos corrientes mencionadas que surgieron tras la Primera Guerra -to-

16 Cfr. Politis, N. Ob. cit., 14 y 38. En efecto, es "le détournement du pouvoir" (i.e., de los fines asignados por el Derecho Internacional) lo que genera la responsabilidad del Estado.

17 Para una revisión histórico-doctrinal de la figura del domaine réservé, cfr. Kolb, $\mathrm{R}$. (2006). "Du domaine réservé: réflexions sur la théorie de la compétence nationale". Revue générale de droit international public, No. 3, 597-646.

18 Cfr. Politis, N. Ob. cit., especialmente 47 y 56.

19 Cfr. Politis, N. Ob. cit., 18, 87-88. 
madas en conjunto. A este representativo autor de la tesis de la soberanía como competencia delegada le dedicaremos, finalmente, unas consideraciones críticas. Postergamos para un próximo estudio el análisis de la teoría de quien, a juicio de Díez de Velasco, ostentaría la paternidad de la ya definitiva concepción competencialista: Charles Rousseau.

\section{Alfred Verdross}

\section{Su ubicación doctrinal}

Dos palabras sobre el ilustre profesor de la Universidad de Viena, "uno de los más grandes juristas desde Savigny"20, cuya trayectoria académica y pública recorre casi todo el siglo pasado, desde el acuñamiento de las expresiones "monismo" y "dualismo" en 1914, hasta su participación en la Convención sobre el Derecho de los Tratados en 1969. Verdross (1890-1980) fue un reconocido discípulo y amigo de Hans Kelsen; pero a diferencia de su maestro, era católico y iusnaturalista. Como se puede colegir aun antes de cualquier desarrollo de su doctrina, su filiación clásica tendrá una incidencia decisiva en aspectos clave de su concepción ético-jurídica-política. Con todo, en la específica cuestión de la soberanía del Estado ante la comunidad y el Derecho Internacionales, sus tesis se acercan más a las de Kelsen y, según intentará mostrarse, son pasibles, en buena medida, de una crítica que los alcanza a ambos ${ }^{21}$.

\section{La unidad del ordenamiento juridico universal}

Verdross, tras la publicación de sus otros trabajos sobre los fundamentos y la naturaleza del orden internacional ${ }^{22}$, dedicó un extenso estudio en 1927 al tema que nos ocupa, en el que depura y perfecciona sus obras ante-

20 El elogio es de Enrique Gómez Araboleya: cfr. Gómez Araboleya, E. (1962). "La teoría del Derecho Internacional en el pensamiento de Hermann Heller". En Gómez Araboleya, E. Estudios de teoría de la sociedad y del Estado. Madrid. IEP, 125-183; aquí, 154 y lo afirma también Truyol y Serra, A. "Soberanía del Estado y Derecho Internacional". Anuario de Filosofía del Derecho, 1958/59, 49-70, aquí 55.

21 Sobre los antecedentes doctrinales de las posiciones de Verdross en la posguerra, cfr. Krabbe, H. (1922). The modern Idea of the State, trad. G. Sabine y W. Shepard. Nueva York-Londres. Appleton. La obra original, en alemán, había aparecido poco antes: (1919). Die moderne Staatsidee. La Haya.

22 Así, Verdross, A. (1923). Die Einheit des rechtlichen Weltbildes. Tübingen. Mohr y (1926). Die Verfassung der Völkerrechtsgemeinschaft. Viena. Springer. 
riores sobre la cuestión. En dicho estudio presenta la que podría ser considerada como la versión definitiva de su monismo internacionalista, tal como cristalizó en la primera etapa de su carrera científica ${ }^{23}$.

Para nuestro autor, la organización de la comunidad internacional ya no posee forma monárquico-aristocrática, como en el medioevo, sino democrática: si antes el órgano soberano lo era el pontífice, actualmente la voluntad suprema residirá en la comunidad internacional, y será creada por el consentimiento general de sus miembros. El conjunto de las reglas así conformadas constituirá el ius gentium ${ }^{24}$. Ahora bien, el mero acuerdo expreso o tácito de los Estados, en sí mismo, no basta para conferir validez a lo pactado, afirma Verdross. En efecto, es necesario un fundamento normativo que torne obligatoria la observación de las reglas emanadas de la voluntad común. Tal fundamento consiste en el principio pacta sunt servanda, norma de Derecho Natural en la que descansa el Derecho de Gentes Positivo ${ }^{25}$.

Verdross, por otra parte, critica la teoría de la autolimitación jurídica del Estado, intrínsecamente vinculada con la de la primacía del Derecho Público Interno sobre el Internacional. Ambas se demuestran incapaces de dar un fundamento de validez al orden internacional. Es pertinente detenerse en la objeción del autor a ésta última. Verdross acepta que gran parte del Derecho Internacional podría fundamentarse en el Derecho Político estatal; pero, agrega, hay normas internacionales que exceden (se oponen) al Derecho Interno. El ejemplo por antonomasia lo constituye la continuidad de las obligaciones del Estado más allá de las mutaciones revolucionarias; Verdross cita jurisprudencia que sienta el principio según el cual tales mutaciones no eximen de las obligaciones contraídas por poderes vigentes en el Estado. Ahora bien, remata Verdross, si todo (“tout entier", destacado original) el Derecho Internacional no puede fundarse en el Derecho Interno, es que dicha fundamentación es inválida ${ }^{26}$.

Ya en este lugar podría observarse que lo mismo vale para la recíproca, pues resulta obvio que idéntica objeción le cabe al monismo internacionalista, en la medida en que el Derecho Interno no puede ser fundado por entero en el Internacional, si no es por el recurso al que acudirá Verdross,

23 Verdross, A. (1928). "Le fondement du droit international". Recueil des cours 16. París. Hachette, 247-323.

24 Una breve acotación terminológica: en este ensayo, escrito en francés -como era la regla hasta la victoria aliada en 1945-, Verdross utiliza ampliamente la locución "droit des gens" (de "ius gentium"), como sinónimo de "Derecho Internacional". Debe repararse en que, en alemán, "Derecho Internacional" se dice "Völkerrecht".

25 Verdross, A. Ob. cit., cap. I, parágs. 1 y 2. Téngase en cuenta que en Die Einheit des rechtlichen Weltbildes, 58 y ss., Verdross había asignado carácter de norma positiva al precepto pacta sunt servanda.

26 Verdross, A. "Le fondement...”. Ob. cit., cap II, esp. \& 6, 268-274. 
de una impugnable delegación de facultades en cabeza de los órganos de los Estados -que veremos más adelante, y con la que él identifica la tesis de la soberanía como competencia delegada. Pero además de ello, podría plantearse que la afirmación de una continuidad de las obligaciones internacionales del Estado (la cual, aun contradiciendo en ocasiones al Derecho Interno vigente, puede seguir sin embargo reclamando objetiva validez) admite ser sostenida apelando a los fundamentos del Derecho Público: o sea, a los principios del orden propio y específico de las comunidades políticas $^{27}$.

Mas continuemos con la argumentación del maestro de Viena. Heinrich Triepel (con quien polemiza el autor a lo largo de su estudio) sostenía un monismo originado en la voluntad de los Estados como creadora del Derecho Internacional. Verdross acepta que, así como la voluntad del Estado es la fuente de las obligaciones internas de la comunidad, a su turno, la fuente deóntica de los acuerdos interestatales deberá ser una voluntad común a los Estados contratantes. Ahora bien, la regla según la cual la voluntad común a varios Estados es considerada un hecho jurídico no puede pertenecer al Derecho Público estatal, sino al Derecho Internacional; además, tal regla debe trascender del plano empírico-positivo. El Derecho de Gentes declara que la voluntad de los órganos de los Estados particulares es su voluntad común, y establece las normas a las que se subordina la voluntad de las partes. Nuestro autor ensalza, como un avance teórico, las doctrinas jurídicas de Krabbe y Kelsen, por el hecho de haber

27 De hecho, es así como Hermann Heller, por ejemplo, remitirá el fundamento de la subjetividad internacional a la volonté générale (como sujeto último de la soberanía del Estado). Dicha volonté générale, o Volkssouveränität en clave estatal, se manifiesta ya en una forma de régimen (p. ej., democrático), ya en otra (p. ej., monárquico) -cfr. Heller, H. (1927). Die Souveränität. Berlín. De Gruyter, 73-76. Asimismo, al enfocar el problema del nacimiento o desaparición del Estado como cuestión esencialmente ajena a la jurisdicción del Derecho Internacional (pues se trata de un caso particular de la específica categoría helleriana de la relación voluntad-norma), el profesor de Frankfurt y Madrid introduce una observación relevante en tal sentido. Pues a diferencia de la desaparición o nacimiento del Estado, que se producen más allá de lo que sentencie el Derecho de Gentes, por el contrario, el Derecho Internacional consuetudinario sí reconoce que, por debajo de las diversas mutaciones constitucionales, late idéntica voluntad de existencia política, la cual se revela -en su originalidad peculiar- en formas que resultan inderivables de una norma internacional alguna (cfr. Die Souveränität, 152-153). Para la concepción del derecho internacional en Heller cfr. Castaño, S (2021). "La teoría de la soberanía de Hermann Heller y su polémica con el pensamiento internacionalista dominante". Anales de la Cátedra Francisco Suárez, en prensa. La afirmación de Heller condice con la posición de la jurisprudencia de su tiempo; y no es ajena a lo sostenido ya por Aristóteles. En efecto, para el Estagirita, un cambio en la forma del régimen no necesariamente compromete la obligación de la comunidad política respecto de su deuda pública con el extranjero: cfr. Aristóteles (1992). Política. Oxford. Ed. Ross. OUP, 1276 b 13-15. 
afirmado que la voluntad de los Estados debía ajustarse a una norma fundamental. Pero toma distancia explícita de su maestro, en la medida en que -observa Verdross- el carácter hipotético asignado por Kelsen a la Grundnorm conspira contra su misma función normativa. En efecto, la norma fundamental kelseniana es pasible de verificación empírica. Aparece (o, mejor dicho, se la presupone como hipótesis) si los hombres conforman en general sus conductas con cierto ordenamiento, que se halla de acuerdo con la hipótesis. Con lo cual, la norma fundamental termina de explicar o describir lo que los hombres de hecho hacen, pero no les señala ni fundamenta deber alguno. He allí el giro marcadamente empirista del formalismo kelseniano. Se comporta a la manera de una hipótesis científico-natural, concluye Verdross sutilmente, y no de una norma fundante de toda obligación.

Así pues, es en el Derecho Natural, entendido en la estela de los fundadores del Derecho Internacional Público (Vitoria, Suárez, Grocio), donde debe buscarse el fundamento último del ordenamiento jurídico universal. En efecto, la norma pacta sunt servanda pertenece al reducido núcleo de preceptos que la razón humana ha descubierto en todo tiempo y lugar. Se trata de un valor evidente, o de una regla ética que se desprende lógicamente de otra regla absoluta ("por ejemplo, de la norma 'suum cuique", aclara Verdross). El Derecho Positivo, en cambio, experimenta mutaciones y cambia con el desarrollo de la civilización: es un valor relativo, dice Verdross. Por el contrario, el valor en que se funda y con el cual se relaciona (la justicia) es absoluto ${ }^{28}$.

No obstante la afirmación de un fundamento de Derecho Natural, con el consiguiente rechazo del positivismo kelseniano, la deriva de su pensamiento llevará a Verdross a tesis próximas a las de su maestro ${ }^{29}$. Es lo que se verá en lo que sigue.

28 Verdross, A. "Le fondement". Ob. cit., cap. III, passim.

29 Sobre este tema en Kelsen pueden ser mencionados, en particular, Kelsen, H. (1923). Hauptprobleme der Staatsrechtslehre entwickelt aus der Lehre vom Rechtssatz. Tübingen. Mohr; Kelsen, H. (1922, $2^{\mathrm{a}}$ ed. 1927). Das Problem der Souveränität und die Theorie des Völkerrechts. Beitrag zu einer Reinen Rechtslehre. Tübingen. Mohr. Para un análisis doctrinal de las posiciones kelsenianas -desde diversas ópticas-, vide Conde, F. J. (1953). El derecho político actual. Madrid. González, cap. V; el ponderado y profundo prólogo de Agostino Carrino a su edición italiana de Souveränität: Carrino, A. (1989). "Prefazione". En Kelsen, H. Il problema de la sovranità e la teoría del diritto internazionale. Milán. Giuffrè, V- XLVI; y von Bernstorff, J. (2016). "Hans Kelsen and the Return of Universalism". En Orford, A. \& Hoffmann, F. (eds.). The Oxford Handbook of the Theory of International Law. Oxford. Oxford University Press, 192-211. 


\section{La primacía del Derecho Internacional}

Intentemos desbrozar la madeja de cuestiones cruciales que se dirimen en lo que Verdross presenta como la "primacía del Derecho de Gentes", enfocando en particular el problema que nos ocupa.

Si la regla pacta sunt servanda es superior a la voluntad de los Estados, afirma Verdross, éstos quedan obligados por las estipulaciones positivas fundadas en aquélla, sea a partir de tratados expresos (Derecho convencional), sea a partir del acuerdo tácito de los Estados (Derecho consuetudinario). En cualquier caso, la regla supraordenada impone el respeto a la palabra dada. Por eso, concluye Verdross, "el Derecho Internacional está supraordenado a los Estados" que le están sujetos. La sociedad internacional, legisladora de ese ordenamiento supremo, es una comunidad democrática en que los miembros contribuyen a la formación de la voluntad general que los obliga. El monismo que propone Verdross busca fundar la unidad jurídica universal sobre la regla axial del Derecho Internacional; para él, la tesis de la primacía de los ordenamientos particulares está llamada al fracaso: pues, a tenor de sus consecuencias, cada ordenamiento estatal, en sí mismo, resultaría independiente de los otros, e independiente, también, del Derecho Internacional.

Enseguida Verdross se aplica a la crítica de la teoría "dualista", tal como, en 1923, Heinrich Triepel la esbozó en polémica contra é ${ }^{30}$. Es aquí cuando aparecen trazas doctrinales pasibles de ser reconducidas al racionalismo juridicista en el que había abrevado el maestro vienés. Resulta imposible -dice en una primera afirmación- tratar al Derecho Internacional y los diversos ordenamientos particulares como sistemas absolutamente separados. En efecto - constata en una segunda proposición-, existe una relación de coordinación entre los diversos Derechos Nacionales, así como una de subordinación de cada uno de ellos ante el Derecho Internacional. A partir de tal subordinación, los Estados dejan de ser absolutamente libres y participan del sistema jurídico de la comunidad internacional: su libertad, aunque vasta, ya no es ilimitada, dado que se halla normada por el Derecho Internacional. Ahora bien -continúa, casi a modo de conclusión-, una libertad que depende de reglas establecidas por una comunidad superior (N.B.: Verdross introduce aquí la existencia de una comunidad) consiste, en realidad, en una competencia conferida por el Derecho subordinante. Esto significa, precisa Verdross, que la esfera de las competencias de cada Estado tiene naturaleza análoga a las de las declaraciones de derechos de las

30 Triepel, H. (1923). "Les rapports entre le droit interne et le droit international". Recueil des Cours 1. París. Hachette, 73-122. 
constituciones modernas, o a las competencias reservadas de los Estados miembros de una Federación: se trata de normas que forman parte de un ordenamiento superior. Para Verdross, decir que el Derecho Internacional Público -Natural o Positivo- limita la potestad del Estado equivale a afirmar que "toda la esfera de actividad del Estado no es sino una competencia sobre la base del Derecho Internacional". De allí que impugne la distinción que hace Triepel entre la subordinación del Derecho Nacional al Internacional y aquélla que existe en el orden federal, donde el Derecho del Estado miembro se subordina al del Estado soberano. Como ejemplos propios del ámbito internacional que probarían tal homogeneidad, Verdross aduce los casos en que los ordenamientos jurídicos nacionales observan la obligación de conformarse con los derechos adquiridos por otros Estados gracias a tratados o a la costumbre. Y, en lo tocante a los deberes que ligan a los individuos, los cuales, por regla general (salvo casos puntuales de territorios gobernados por órganos internacionales) emanan del Derecho Interno, Verdross explica que la facultad de los Estados para gobernar a sus ciudadanos deriva del previo reconocimiento de tal competencia por parte del Derecho Internacional. La comunidad internacional, remata Verdross, posee la "competencia de la competencia absoluta" para aumentar o disminuir las competencias de las comunidades (en realidad, sus órganos) subordinadas. No puede pasarse por alto el hecho de que "Kompetenz-Kompetenz" ha sido la locución típica de la doctrina alemana para designar a la soberanía ${ }^{31}$.

\section{La unidad jurídica universal}

En esas últimas afirmaciones consignadas supra se hace ya evidente la impronta racionalista a que habíamos aludido. Como consecuencia de ello, la dimensión política aparece absorbida por la jurídica; o, lo que es lo mismo, el Estado resulta asimilado a una competencia, y el poder político a una norma. En las páginas siguientes, Verdross termina de acentuar tal línea de pensamiento. En la cima de la pirámide jurídica se halla la regla fundamental pacta sunt servanda, que instituye la autoridad suprema creadora de las

31 Verdross, A. "Le fondement...”. Ob. cit., cap. IV, passim. Véase cómo conceptualiza Kelsen, por ejemplo, el territorio del Estado: “[...] podemos definir el territorio del Estado como aquel espacio en el que el Estado está autorizado por el Derecho Internacional general para realizar todos los actos dispuestos por su Derecho Nacional o, lo que es lo mismo, el espacio en que de acuerdo con el Derecho Internacional general los órganos determinados por un orden jurídico nacional están facultados para hacer cumplir este orden": Kelsen, H. (1959). Principles of International Law, New York, Rinehart \& Co., p. 209. Esta coincidencia en las conclusiones abona la hipótesis de que la genealogía teórica decisiva en Verdross no es la del iusnaturalismo clásico, sino la del racionalismo inviscerado en el kelsenismo. 
normas positivas más altas, es decir, del Derecho Internacional consuetudinario y convencional. Por su parte, las competencias internas de cada Estado se ven acotadas por las reglas consuetudinarias del Derecho de Gentes; dentro, pues, de los límites que éste impone, se desarrollarán los ordenamientos jurídicos particulares. Verdross, en consecuencia, afirma que el Derecho de Gentes no consiste en una esfera aislada dentro del ámbito jurídico, sino en el grado supremo de la pirámide de un sistema unitario. El Derecho de los Estados, en general, es el ejecutor del Derecho de Gentes. En efecto, cuando la comunidad internacional no actúa a través de órganos propios, son los Estados subordinados los obligados a concretar por medio de sus órganos las reglas abstractas del Derecho de Gentes. Así pues, existen comunidades indirectamente subordinadas al Derecho de Gentes (los Estados miembros del Estado federal), y otras directamente subordinadas a él. La potestad de las primeras no es suprema, por hallarse sujeta al Derecho estatal; pero tampoco es suprema la potestad del Estado, afirma Verdross, ya que consiste en una competencia conferida directamente por el Derecho de Gentes. De acuerdo con esto, la llamada soberanía del Estado designa el hecho de no hallarse éste subordinado a otro poder fuera del Derecho Internacional.

Para Verdross, las obligaciones internacionales que vinculan a los Estados entre sí no pueden fundarse sino a partir de la concepción de la autoridad estatal como competencia reconocida por un superior (el Derecho Internacional). Tras interpretar en este espíritu las tesis de los grandes escolásticos, Verdross concluye: “[...] su soberanía (la de los Estados) no es una soberanía absoluta"; y de allí extrae la consecuencia: la soberanía "no es sino una competencia dada a los Estados por el Derecho Natural y el Derecho de Gentes Positivo"32. Todo poder soberano deriva y es creación del Derecho de Gentes, a cuyas reglas debe conformarse. En este lugar de la argumentación, el autor aduce una sentencia de la Corte Permanente de Justicia, que cabrá comentar: "La cuestión de saber si una cierta materia entra dentro del dominio exclusivo del Estado es una cuestión esencialmente relativa: depende del desarrollo de las relaciones internacionales" (el autor cita la "Opinión Consultiva sobre Túnez y Marruecos", nº 4, p. 24).

La última conclusión del ensayo de Verdross pone su doctrina en línea con la de Jellinek y la de Carré, en lo que toca a la cuestión de negar a la potestad soberana como una nota de la estatalidad ${ }^{33}$. En efecto, la teoría que

32 Verdross, A. "Le fondement...", 312-3.

33 Lo dicho se aplica a ambas autoridades en el sentido de que tanto Jellinek como Carré afirman la existencia de estados no soberanos: cfr. Jellinek, G. (1996). Die Lehre von den Staatenverbindungen. $2^{\mathrm{a}}$ ed (ed. original 1882). Goldbach. Keip Verlag, 34-58; Jellinek, G. Allgemeine Staatslehre, 472-475; Raymond Carré de Malberg, R. (1960). Contribution à la Théorie Général de l'État. $2^{\mathrm{a}}$ ed. (ed. original 1920). T. I. París. CNRS, 158 y ss. 
venimos exponiendo rechaza la existencia de una diferencia específica ("essentielle") entre el Estado y otras asociaciones de Derecho Público. En el ámbito del Derecho, dice Verdross, sólo se dan diferencias jurídicas. Ahora bien, la única diferencia de tal raigambre que afecta a las diversas asociaciones de Derecho Público estriba en que unas se subordinan directamente al Derecho de Gentes, mientras otras no. Y no es dable, por otra parte, señalar diferencias extrajurídicas entre el Estado y los otros grupos. Verdross cierra su estudio justificando un lema de la época en ciertos ámbitos doctrinales: la propuesta del abandono de la noción de soberanía. Sin embargo, termina aceptando finalmente el uso del término, a condición de que se lo entienda como competencia delegada por el Derecho Internacional ${ }^{34}$.

\section{Síntesis de las posiciones de Alfred Verdross sobre nuestro tema: la soberanía como competencia jurídica delegada}

Para el maestro de Viena, la libertad de que gozan los Estados se halla limitada por el Derecho Internacional; ahora bien, una libertad así limitada equivale una competencia conferida por el derecho subordinante ${ }^{35}$.

En Verdross, es necesario reiterarlo, la existencia del orden jurídico internacional equivale a la existencia de una comunidad superior, dotada de potestades supremas ${ }^{36}$. Así pues, los ordenamientos jurídicos de los Estados se hallan en una situación análoga (con analogía de proporcionalidad propia) a la de las declaraciones de derechos de las constituciones políticas, que consagran privilegios intangibles; o a la de los derechos reservados de los Estados miembros de una federación. Tanto unas como otros existen en virtud de la constitución del Estado ${ }^{37}$. En conclusión: el Derecho Interno está subordinado al Internacional, cual si se tratara de una única comunidad política que los contuviese a ambos.

De allí se siguen una serie de consecuencias institucionales de profundo alcance. Los Estados están obligados a conformar su sistema normativo, la constitución incluso, al Derecho de Gentes. Ahora bien, si las normas de Derecho Interno que contrarían el Derecho Internacional siguen conservan-

34 Verdross, A. "Le fondement...”. Ob. cit., cap. V y VI, passim.

35 Verdross, A. "Le fondement...”. Ob. cit., 291.

36 Lo cual se explica desde la perspectiva kelseniana de Verdross, por cuanto el Estado no es sino la personificación del ordenamiento jurídico. Para esta idea como tópica en las obras de Kelsen cfr., por todas, Kelsen, H. (1934). Compendio de Teoría General del Estado, est. prel. L. Recaséns Siches, trad. L. Recaséns Siches y J. de Azcárate. Barcelona. Bosch, 123-124.

37 Cfr. Verdross, A. "Le fondement...”. Ob. cit., 291-2. 
do validez, si no son ipso iure nulas, eso se debe a la coyuntura histórica en que se halla el Derecho Positivo, a la circunstancia accidental de que en ese momento el Derecho de Gentes sólo obligue indirectamente. Sea como fuere, el Derecho Internacional podría válidamente restringir las competencias del Estado y dirigirse directamente a los individuos ${ }^{38}$.

La pirámide jurídica tiene en su cima la regla fundamental (de Derecho Natural ${ }^{39}$ ) pacta sunt servanda; luego viene el Derecho Positivo supremo: los tratados entre los Estados o, más en general, los acuerdos expresos o tácitos entre Estados (entre éstos últimos entraría el Derecho consuetudinario). Esas reglas internacionales limitan las competencias de los Estados en el momento de instituir su Derecho Interno. Por su parte, el Derecho de Gentes es ejecutado no sólo por los Estados sino también, en ciertas circunstancias, por los organismos internacionales ${ }^{40}$. Así pues, el Derecho Positivo supremo (i.e., el Derecho de Gentes) rige siempre y en todo lugar: ya sea puesto en vigor directamente -por las mismas instituciones de la comunidad internacional-, ya indirectamente -por los Estados ${ }^{41}$.

Por último, Verdross ensaya otra explicación convergente para apuntalar su tesis de subordinación del Derecho Interno al Internacional. La soberanía del Estado se da allí donde el Estado no tiene superior temporal. Pero como la voluntad del Estado no es fuente última del Derecho (o sea, de su juridicidad, entendida como valor jurídico) -puesto que esa voluntad política debe sujetarse a normas deónticamente superiores para resultar válida-; luego la soberanía es competencia delegada por el Derecho Natural (y por el de Gentes, agrega Verdross). Pone el ejemplo del derecho de la guerra, en el que los Estados se adecuan a los usos vigentes, tal como los establece el Derecho de Gentes. Así, la soberanía en su sentido originario es la competencia que deriva directamente del Derecho de Gentes: no está sujeta a ningún otro "poder" (pues con un poder se equipara aquí en última instancia al Derecho Internacional) fuera del Derecho de Gentes, sentencia nuestro autor ${ }^{42}$. Por esa razón la soberanía no puede sustraerse a una obligación internacional. Como una competencia más, la soberanía sólo tiene una mayor amplitud que las competencias emanadas del Derecho estatal; es decir que guarda con ellas una mera diferencia de grado ${ }^{43}$.

38 Cfr. Verdross, A. "Le fondement...”. Ob. cit., 295.

39 Recordemos que Verdross -a la par de destacadísimo discípulo de Kelsen y, sobre todo en esa época, heredero de la forma mentis de su maestro- era un jusnaturalista católico que reclamaba genealogía secundoescolástica para su doctrina.

40 Cfr. Verdross, A. "Le fondement...”. Ob. cit., 298 y ss.

41 Cfr. ibídem, 306.

42 Cfr. ibídem, 312-315.

43 Cfr. ibídem, 319. 


\section{La cuestión en el Derecho convencional de las organizaciones internacionales y en la jurisprudencia internacional contemporáneos a la obra analizada. Dos ejemplos}

El artículo 15 del Pacto de la Sociedad de Naciones estipulaba el procedimiento a seguir en los diferendos entre Estados miembros cuando tales diferendos no eran pasibles de solución arbitral o jurisdiccional. En el inciso $8^{\circ}$, el Pacto se refiere a "diferendos que versan sobre una cuestión que el Derecho Internacional deja a la competencia exclusiva (compétence exclusive)" de los Estados. Con todo, las provisiones del artículo, fuerza es decirlo, en ningún momento comprometen la independencia de los Estados, sea de los miembros del Consejo, sea -lo cual es más relevante- de los propios protagonistas del conflicto ${ }^{44}$.

Pareja consideración merece el leading case "Lotus"45. Allí, la Corte Permanente de Justicia Internacional, es verdad, sostiene que "[t]odo lo que se puede pedir a un Estado es no rebasar los límites que el Derecho Internacional traza a su competencia". Sin embargo, en el aquende, el Estado es libre de actuar y su título es la soberanía. En efecto, las reglas que ligan a los Estados proceden de la voluntad de éstos, la cual se manifiesta en convenciones o en usos aceptados generalmente, que se considera consagran los principios de Derecho, establecidos para regular la coexistencia o en vista de objetivos (buts) comunes. Pero no se presumen las limitaciones a la independencia; la limitación primordial para los Estados consiste en abstenerse de todo ejercicio de su potestad en territorio de otro Estado. En síntesis, la amplia libertad que el Derecho Internacional deja a los Estados sólo es coartada en algunos casos por reglas prohibitivas. En todos los otros supuestos, el Estado es libre, sin necesidad de reglas permisivas que lo respalden en cada caso para actuar.

\section{La última doctrina de Verdross}

Es necesario y debido puntualizar que estas tesis del ilustre jurista experimentaron en las décadas siguientes una modulación y evolución, que

44 Se consulta el texto del Pacto en Ottlik, G. (1927). Annuaire de la Société des Nations 1920-1927. Lausanne et Genève. Payot, 26-30.

45 Cfr. Publications de la Cour Permanente de Justice Internationale, Série A, No 10, le 7 septembre 1927, Recueil des Arrêts, "Affaire du Lotus" -vide esp. 18 y 19. 
de alguna manera amortiguaron los alcances y las aristas propias del racionalismo de su primera época.

En Völkerrecht -obra de síntesis y de madurez del rector de Viena-, Alfred Verdross introduce el tratamiento del Estado, de su independencia y de la supremacía de su poder, cuando aborda el tema del ámbito de validez del ordenamiento jurídico internacional ${ }^{46}$. Es así como el Estado es reconocido, en línea con la tradición clásica, como "comunidad perfecta" que "se gobierna plenamente a sí misma". Si bien a renglón seguido aparece la que para el autor constituye la nota típica del ordenamiento del Estado, en tanto sujeto del Derecho Internacional: su vinculación directa con ese ordenamiento; pero ello aquí no significa que la existencia de los Estados quede supeditada a la decisión del Derecho Internacional, el cual estaría entonces facultado para sustraer toda materia a la regulación de los Estados y, así, disponer su colapso (como lo pretendía Kelsen). Más aún: para Verdross, impedir el autogobierno del Estado equivaldría a suprimir el propio Derecho Internacional. Nuestro autor elenca, asimismo, una serie de derechos del Estado, inherentes a él en tanto inmediatamente vinculado con el ordenamiento internacional: derecho a la independencia, al respeto de la supremacía territorial y al honor, a la comunicación. Mas sin perjuicio de todo lo asentado, es el ordenamiento internacional el que regula las competencias de los Estados, y las competencias presuponen, a su vez, los distintos ámbitos de validez, puesto que aquéllas se extienden hasta donde lleguen éstos. Ahora bien, es justamente el Derecho Internacional el que delimita dichos ámbitos, "en el tiempo y en el espacio, sobre las personas y sobre las cosas”. Sin embargo, señala el rector de Viena, los principios que atañen a la delimitación de los ámbitos personal y material no son tan claros como los dos primeros. Luego, las reglas de nacionalidad, y el reconocimiento, continuidad, sucesión, extinción, soberanía territorial (v. gr., adquisición, pérdida, limitación) del Estado; así como todo ámbito en que pueda darse una actividad ad extra de la comunidad política (p. ej., en alta mar) quedan bajo el contralor y la delimitación del Derecho Internacional Público ${ }^{47}$.

46 Cfr. Verdross, A. (1974). Derecho Internacional Público. $4^{\mathrm{a}}$ ed., trad. castellana A. Truyol y Serra. Madrid. Aguilar.

47 Cfr. Verdross, A. Derecho Internacional Público. Ob. cit., caps. X, XI y XII. 


\section{Consideraciones críticas sobre la doctrina temprana de Verdross}

Si se quisiera sintetizar el fondo de la posición de Verdross respecto de la naturaleza de las relaciones entre la comunidad internacional y los Estados particulares; o, más precisamente, identificar la filiación doctrinal de su pensamiento en este tema, cabría reiterar que en el ilustre maestro de Viena conviven la tradición iusnaturalista secundoescolástica con el racionalismo juridicista que tuvo su cima en Kelsen. Pero si acaso se intentara determinar cuál de ambas tiene el papel protagónico (definitorio) dentro de su monismo, tal vez habría que inclinarse por señalar a la componente racionalista.

Las observaciones que cabe formular a Verdross consisten, en buena medida, en modulaciones diversas de una cuestión central: la confusión entre sociedad humana y decisión humana, por un lado, y orden jurídico, por otro. Es decir, el haber atribuido notas propias de los actos humanos sociales de imperio (fundados, a su vez, en la existencia de una comunidad -en sentido estricto-) a los efectos normativos de esas acciones. Este juridicismo falla por considerar a la parte como el todo, v. gr., por absorber en el Derecho la totalidad del orden político, tal como lo había hecho ya Kelsen. Observemos cómo se plantea esta asunción teórica de fondo.

Aceptemos, en línea con el iusnaturalismo clásico y cristiano, que hay un Derecho Natural común a todo hombre o, para decirlo con Verdross, común a la humanidad. A ese Derecho le está deónticamente sujeto todo Derecho Positivo y, por lo mismo, el Derecho sancionado por los Estados particulares, tanto en las relaciones que los vinculan entre sí cuanto en la organización interna que adopten. Ahora bien, el Derecho Natural no es un derecho emanado de y sancionado por una sociedad. En efecto, la humanidad no es "sociedad" sino en sentido impropio, por cuanto el conjunto o sumatoria de los individuos de la especie humana no se halla constituido en un grupo jerárquicamente organizado que persiga un fin común. Esa realidad ontológicamente múltiple posee unidad en la línea del ser, no del obrar. En concreto, la comunidad de la especie humana no es la que deriva de un fin causalmente común, sino la de compartir idéntica naturaleza (la humana): no hay unidad práctica (i.e., social) entre ellos ${ }^{48}$. El ilustre jurista de Viena, al absorber la realidad práctica de la esfera política (social en sentido estricto) dentro de un entramado jurídico que no arraiga en la inte-

48 Sobre este punto clave, en última instancia ontológico, cfr. Soaje Ramos, G. (2018). El grupo social. Madrid. Marcial Pons, esp. 31-32; Castaño, S. (2005). El Estado como realidad permanente. Buenos Aires. La Ley, esp. 6-8. 
gración en un grupo político-institucional mayor, confunde derecho supremo con sociedad suprema. Y a partir de esa premisa se seguirá la mayor parte de las conclusiones objetables de Verdross.

Así, según Verdross, la libertad de acción del Estado se asimila a una competencia reconocida por la comunidad internacional. Cada Estado particular pasa a ser órgano con una competencia jurídica delimitada por el Derecho subordinante ${ }^{49}$. A su vez, el Derecho vigente en toda comunidad política es creación (por lo menos indirecta) del Derecho de Gentes, del que deriva su validez. Ahora bien, en la cúspide de la pirámide jurídica se halla el principio pacta sunt servanda. Lo cual significa que la ingente pluriformidad de los ordenamientos es causada por un principio generalísimo y máximamente abstracto. Esto es tanto más insostenible cuanto que tal principio no indica más que la obligación de respetar los tratados, la bona fides, o sea, se trata de una regla apta para fundar la legitimidad de las relaciones interestatales en su coordinación horizontal, pero no la totalidad del Derecho Interno de cada Estado. En el caso de que hubiese un solo Estado sobre la tierra, la regla de Verdross mostraría aún más su vaciedad, sin que por ello dejara de ser perentorio para esa comunidad el organizar su modo de vida político y jurídico. Es pertinente resaltar, con respecto a la supremacía jurídica del pacta sunt servanda en Verdross, que no por casualidad la propuesta regla suprema del Derecho de Gentes expresa el fundamento de validez de relaciones de específica índole contractual. Aquí la pretensión teórica de Verdross aparece condicionada por la realidad objetiva. En efecto, en esa norma puede descansar la obligatoriedad de la coordinación interestatal, mas no un orden jurídico total que incluya relaciones de subordinación, como aquéllas que dan lugar a la delegación de competencias en órganos determinados. Ahora bien, si la norma básica del Derecho Internacional Público expresa el fundamento de relaciones de coordinación es precisamente porque no existe una sociedad internacional sensu stricto, fundada en relaciones de integración, como tampoco existe -como consecuencia de la integración política- una autoridad política internacional.

Parece cierto, pues, que la filiación secundoescolástica pretendida por Verdross para su doctrina resulta harto discutible, por lo menos si se para mientes en la nota racionalista y abstractista que signa su posición acerca de la Política y del Derecho. Las citas de Vitoria y Suárez que aduce en abono de ésta sólo dicen que la soberanía no consiste en un poder absoluto, ad utrumlibet, sino que la potestad del Estado debe ordenarse según las

49 La matriz originaria de esta asimilación del Estado a un órgano con competencias jurídicamente delimitadas se halla, como dijimos supra, en Jellinek, G. Allgemeine Staatslehre. Ob. cit., cap. XVI, II, 3: "Die Rechtsstellung der Staatsorgane”, 546-551. 
exigencias del Derecho Natural. Ahora bien, la afirmación clásica no equivale a la tesis de una derivación axiomática de la totalidad del Derecho (de los Estados) a partir de una norma abstracta. En efecto, la noción de "autoridad suprema", que Verdross identifica con la regla fundamental, resulta irreductible a un principio general, desde el momento en que la función de la autoridad consiste en la concreción prudencial de las normas con miras al bien común. Tal exigencia pone sobre el tapete el papel de los factores tradicionales y volitivos (además de los racionales), conduciéndose entre alternativas de contornos particularísimos, signados por el hic et nunc empírico: circunstancias históricas, raciales, culturales, geográficas, más un cúmulo de contingencias incodificables -y la libertad humana decidiendo a partir de ello. Toda norma supone un normador, con el que no se identifica: el normador es un ser personal, y la norma, un ente de razón. Por otro lado, la obligatoriedad del precepto jurídico se funda en los títulos de quien ejerce la potestad de mando ${ }^{50}$.

En las consideraciones supra desgranadas se encierran varias cuestiones más que interesantes, en perspectiva de principios -que sólo dejaremos mencionadas. En primer lugar, el hecho de que ciertas derivas del iusnaturalismo no resultan inconciliables con las geometrías legales de cuño moderno y que se consuman en el positivismo normativista ${ }^{51}$. Asimismo, que la tesis aristotélica de politicidad natural -como en general fue asumida por la segunda escolástica-52, en tanto afirma las exigencias de un grupo social autárquico, impide resolver la realidad social del orden político (i.e., de la comunidad política: societas perfecta) en un haz de normas -el cual, además, se sujetaría a un haz mayor como la parte al todo ${ }^{53}$. Es así como desde otra

50 Este último aserto, si de escolástica se trata, se respalda en Tomás de Aquino. Summa Theologiae, II-IIae., 105, 2 c.

51 Para la idea de "geometría legal", vide Gentile, F. (2001). El ordenamiento jurídico, entre la virtualidad y la realidad. Madrid. Marcial Pons.

52 Sobre las fuentes aristotélicas de Vitoria y Suárez, cfr. Truyol y Serra, A. (1999). "Vitoria et la tradition scolastique". En Zarka, Y. Ch. (ed.). Aspects de la pensée médiévale dans la pensée politique moderne. Paris. PUF, esp. 73; Pécharman, M. (1999). "Les fondements de la notion de l'unité du peuple selon Suárez”. En Zarka, Y. Ch. (ed.). Aspects de la pensée médiévale... Ob. cit., esp. 115-120. Respecto de la específica cuestión de la perspectiva aristotélica en la concepción vitoriana de la comunidad política, cfr. Janssen, D. (2001). "Die Theorie des gerechten Krieges im Denken des Francisco de Vitoria”. En Janssen, D. Die Ordnung der Praxis. Neue Studien zur spanichen Spätscholastik. Tübingen. Max Niemeyer, esp. 217-218; Haggenmacher, P. (1988). "La place de Vitoria parmi les fondateurs du droit international". En AA. VV. Actualité de la pensée juridique de Francisco de Vitoria. Bruselas. Bruylant, esp. 49.

53 Las afirmaciones de Vitoria, Suárez y Grocio no dejan dudas al respecto. "Una república o comunidad perfecta es la que es por sí misma un todo; esto es, la que no es parte de otra república, sino que tiene sus propias leyes, su propio régimen y sus propios gobernantes": Vitoria, F. (1934). Relectio posterior De Indis II, $7^{\text {a }}$ edición de las Relecciones de Getino, L. A. Obras 
vertiente doctrinal, pero también conteste en sostener el papel de la agrupación política como unidad práctica ("Entscheidungs- und Wirkungseinheit"), Hermann Heller reafirmará el lugar del Estado soberano como quicio del orden internacional ${ }^{54}$.

La cita de la CPJI, por su parte, constata que las materias reservadas como de dominio exclusivo de los Estados dependerá de los diversos grados de interdependencia, colaboración, gestión en común -y, en un futuro, o más bien por vía de hipótesis, integración- que se vaya operando históricamente en el seno de la denominada comunidad internacional. Mas no avala la atribución de naturaleza social (sensu stricto, como un Estado) al pluriverso político mundial.

Todo lo dicho explica la analogía de proporcionalidad propia, que Verdross esgrime contra Triepel, entre la subordinación del Estado miembro respecto del Estado federal y la que existe entre el Estado soberano y la comunidad internacional (absorbida por una norma abstracta). No hay, para Verdross, solución de continuidad ni "cierre" práctico en el nivel del Estado. Para reconocerlo, era ineludible advertir la presencia de un factor de decisión prudencial, fundado, a su vez, en la necesidad de concreción de una cierta forma autárquica de la convivencia. Pero la comprehensión integral de la realidad política ha resultado habitualmente desconocida por el more geometrico jurídico de las escuelas racionalistas.

de Francisco de Vitoria. Madrid. La Rafa, II, 7; “[1]a república temporal es una república perfecta e íntegra; luego no está sujeta a nada exterior a ella, porque si así fuera no sería íntegra. Por eso puede instituir para sí un príncipe que en modo alguno está sujeto a otro en materia temporal": Vitoria, F. de (1934). "De potestate ecclesiastica”. En Getino. Ob. cit., I, V, 4; “cuando en tal principado o república hay un tribunal en el que terminan todas las causas de ese principado, y no es posible apelar a otro tribunal superior. Pues cuando hay lugar a apelación se da el signo de principado imperfecto, ya que la apelación es un acto del inferior al superior": Suárez, F. (1954). "Disputatio XII De Bello". Edición Pereña, L. Teoría de la guerra en Francisco Suárez. Madrid. CSIC, sec. II, n. 4. Para Suárez, la exigencia de que la decisión sobre las hostilidades debe provenir de la autoridad competente -so pena de tornar injusta la contienda- se identifica sin más con la tesis de que la única instancia facultada para la declaración de guerra es la autoridad de la sociedad perfecta, en la persona del titular de la suprema potestas (Suárez, F. "Disputatio XII De Bello". Ob. cit., sec. II, n. 4). Parejos juicios se hallan en Grocio. La condición de Estado depende de su soberanía, que le permite conservar su libertad exterior e interior. La soberanía (summa potestas, summum imperium) consiste en la independencia de los actos de gobierno de la sociedad respecto de todo otro poder superior, "de suerte que no pueden ser anulados por ninguna otra voluntad humana": Grocio, H. (1984). "De iure belli ac pacis". En la versión de Barbeyrac, J.. Le droit de la guerre et de la paix. Amsterdam. Pierre de Coup, 1734, L. I, cap. III, \& VII -se utiliza la reedición de la Universidad de Caen.

54 Para una comparación entre ambas corrientes doctrinales, puede verse Castaño, S. (2014). "Souveräne Staatsgewalt nach der Lehre Hermann Hellers und potestas superiorem non recognoscens bei Vitoria und Suárez im Vergleich”. Archiv für Rechts- und Sozialphilosophie, 100 (1), 77-93. 


\section{A modo de conclusión}

Retomando lo planteado, hagamos por último una breve cifra conclusiva. Verdross asocia o comunica la supremacía deóntica del Derecho Natural al Derecho de Gentes, y a continuación traslada dicha supremacía a la comunidad internacional y a sus órganos. Luego, la soberanía del Estado estaría obligatoriamente subordinada a esos órganos tanto como se encuentra deónticamente subordinada al Derecho Natural. La transposición de realidades y sus consecuencias normativas no dejan de ser advertibles: a partir de la base de atribuir la naturaleza, propiedades y exigencias de una sociedad política al Derecho Internacional (o a la "sociedad" internacional) -en el Verdross de 1928, apelando al Derecho Natural; aunque no sea imprescindible hacerlo_ ${ }^{55}$, el resultado es la construcción de un ordenamiento normativo supremo que genera relaciones de subordinación estrictas y convierte, por ende, a los Estados en miembros de una cuasi-federación.

Cabe proponer, finalmente, que si la tesis de que la soberanía del Estado consiste en una delegación de competencias operada por el Derecho Internacional Público ha de sostenerse en algo más que la pura vigencia teórica, no es en la formulación racionalista del primer Verdross (o similares) donde encontrará su más incuestionable fundamento de validez objetiva.

\section{Bibliografía}

"Affaire du Lotus". En Publications de la Cour Permanente de Justice Internationale, Série A, No 10, le 7 septembre 1927, Recueil des Arrêts.

Aristóteles (1992). Política. Oxford. Ed. Ross. OUP.

Cagni, H. (1999). La guerra hispanoamericana y el inicio de la globalización, pról. de Abel Posse. Buenos Aires. CAEE-Universidad de Sevilla.

Carré de Malberg, R. (1960). Contribution à la Théorie Général de l'État. París. CNRS.

Carrillo Salcedo, J. (1995). Soberanía de los Estados y Derechos Humanos en Derecho Internacional contemporáneo. Madrid. Tecnos.

Carrino, A. (1989). "Prefazione". En Kelsen, H. Il problema de la sovranità e la teoría del diritto internazionale. Milán. Giuffrè, V-XLVI.

Castaño, S. (2005). El Estado como realidad permanente. Buenos Aires. La Ley.

Castaño, S. (2014). "Souveräne Staatsgewalt nach der Lehre Hermann Hellers und potestas superiorem non recognoscens bei Vitoria und Suárez im Vergleich". Archiv für Rechts- und Sozialphilosophie, 100 (1), 77-93.

Castaño, S. (2019). El Estado en el orden internacional. Buenos Aires: EDUCA.

55 Ver supra, nota 25. 
Castaño, S. (2021). "La teoría de la soberanía de Hermann Heller y su polémica con el pensamiento internacionalista dominante". Anales de la Cátedra Francisco Suárez (en prensa).

Conde, F. J. (1953). El derecho político actual. Madrid. González.

Convención Panamericana sobre los Deberes y los Derechos de los Estados. En https://www.dipublico.org/14602/convencion-sobre-derechos-y-deberes-de-losestados-septima-conferencia-internacional-americana-montevideo-1933/. Fecha de consulta: 25-6-2021.

Diez de Velasco, M. et al. (2013). Instituciones de Derecho Internacional Público. C. Escobar Hernández ed. Madrid. Tecnos.

Duguit, L. (1921). Traité de Droit Constitutionnel. París. Fontemoing.

Gentile, F. (2001). El ordenamiento jurídico, entre la virtualidad y la realidad. Madrid. Marcial Pons.

Gómez Araboleya, E. (1962). "La teoría del Derecho Internacional en el pensamiento de Hermann Heller". En Gómez Araboleya, E. Estudios de teoría de la sociedad y del Estado. Madrid. IEP, 125-183.

Grocio, H. (1984). De iure belli ac pacis. En la versión de Barbeyrac, J. Le droit de la guerre et de la paix. Amsterdam. Pierre de Coup, 1734 -se utiliza la reedición de la Universidad de Caen.

Haggenmacher, P. (1988). "La place de Vitoria parmi les fondateurs du droit international”. En AA. VV. Actualité de la pensée juridique de Francisco de Vitoria. Bruselas. Bruylant, 32-45.

Heller, H. (1927). Die Souveränität. Berlín. De Gruyter.

Janssen, D. (2001). "Die Theorie des gerechten Krieges im Denken des Francisco de Vitoria". En Janssen, D. Die Ordnung der Praxis. Neue Studien zur spanichen Spätscholastik. Tübingen. Max Niemeyer, 210-229.

Jellinek, G. (1905). Allgemeine Staatslehre. Berlín. O. Häring.

Jellinek, G. (1996). Die Lehre von den Staatenverbindungen. Goldbach, Keip Verlag.

Kasirer, N. (1987). "A Reading of Georges Scelle's Précis de droit des gens”. Annuaire Canadien de Droit International. Vol. 24, 372-385.

Kelsen, H. (1923). Hauptprobleme der Staatsrechtslehre entwickelt aus der Lehre vom Rechtssatz. Tübingen. Mohr.

Kelsen, H. (1927). Das Problem der Souveränität und die Theorie des Völkerrechts. Beitrag zu einer Reinen Rechtslehre. Tübingen. Mohr.

Kelsen, H. (1934). Compendio de Teoría General del Estado, est. prel. L. Recaséns Siches, trad. L. Recaséns Siches y J. de Azcárate. Barcelona. Bosch.

Kelsen, H. (1959). Principles of International Law. New York. Rinehart \& Co.

Kolb, R. (2006). "Du domaine réservé: réflexions sur la théorie de la compétence nationale". Revue générale de droit international public, No. 3, 597-646.

Koskenniemi, M. (2001). The Gentle Civilizer of Nations: The Rise and Fall of International Law 1870-1960. Cambridge. Cambridge University Press.

Krabbe, H. (1922). The modern Idea of the State, trad. G. Sabine y W. Shepard. Nueva York-Londres. Appleton.

Pacte de la Société des Nations (texto en vigor en 1927). En Ottlik, G. (1927). Annuaire de la Société des Nations (1920-1927). Lausanne-Genève. Payot. 
Pastor Ridruejo, J. (2001). Curso de Derecho Internacional Público y Organizaciones Internacionales. Madrid. Tecnos.

Pécharman, M. (1999). "Les fondements de la notion de l'unité du peuple selon Suárez”. En Zarka, Y. Ch. (ed.). Aspects de la pensée médiévale dans la pensée politique moderne. Paris. PUF, 105-129.

Pecourt, E. (1962). La soberanía de los Estados ante la organización de las Naciones Unidas. Barcelona. Sagitario.

Politis, N. (1926). "Le problème des limitations de la souveraineté nationale et la théorie de l'abus de droit dans les rapports internationaux". Recueil de Cours 6. París. Hachette, 5-121.

Remiro Brotóns, A. et al. (2010). Derecho Internacional. Curso general. Valencia. Tirant lo Blanch.

Rousseau, Ch. (1949). "L' indépendance de l'État dans l'ordre international”. Recueil des Cours, 73. París. Sirey, 167-253.

Rousseau, Ch. (1958). "Principes de droit international public". Recueil des Cours 93. La Haya. M. Nijhoff, 369-559.

Rousseau, Ch. (1971). Droit International Public. París. Dalloz.

Scelle, G. (1919). Le pacte des Nations et sa liaison avec le Traité de Paix, préf. de L. Bourgeois. París. Recueil Sirey.

Scelle, G. (1932 y 1934). Précis de droit des gens. París. Sirey; reeditado por el CNRS: París, 1984.

Soaje Ramos, G. (2018). El grupo social. Madrid. Marcial Pons.

Suárez, F. (1954). "Disputatio XII De Bello". En la edición de Pereña, L. Teoría de la guerra en Francisco Suárez. Madrid. CSIC.

Tomás de Aquino (1894). Summa Theologiae, II-IIae.

Triepel, H. (1923). "Les rapports entre le droit interne et le droit international". Recueil des Cours 1. París. Hachette, 73-122.

Truyol y Serra, A. (1999). "Vitoria et la tradition scolastique”. En Zarka, Y. Ch. (ed.). Aspects de la pensée médiévale dans la pensée politique moderne. Paris. PUF, 70-89.

Truyol y Serra, A. (1958/9). "Soberanía del Estado y Derecho Internacional". Anuario de Filosofía del Derecho, 1958/59, 49-70.

Verdross, A. (1923). Die Einheit des rechtlichen Weltbildes. Tübingen. Mohr.

Verdross, A. (1926). Die Verfassung der Völkerrechtsgemeinschaft. Viena. Springer.

Verdross, A. (1928). "Le fondement du droit international". Recueil des cours 16. París. Hachette, 247-323.

Verdross, A. (1974). Derecho Internacional Público. $4^{\mathrm{a}}$ ed., trad. castellana A. Truyol y Serra. Madrid. Aguilar.

Vitoria, F. de (1934). "De potestate ecclesiastica". En la edición de las Relecciones de Getino, L. A. Obras de Francisco de Vitoria. Madrid. La Rafa.

Vitoria, F. (1934). "Relectio posterior De Indis". En la edición de las Relecciones de Getino, L. A. Obras de Francisco de Vitoria. Madrid. La Rafa.

Von Bernstorff, J. (2016). "Hans Kelsen and the Return of Universalism". En Orford, A. \& Hoffmann, F. (eds.). The Oxford Handbook of the Theory of International Law. Oxford. OUP. 